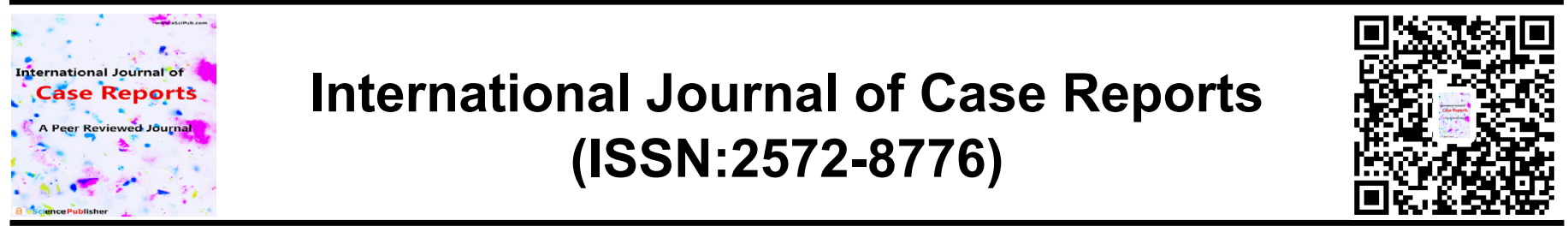

\title{
THE COEXISTENCE OF A PRE-AURICULAR SINUS WITH POST- AURICULAR DERMOID CYST
}

\author{
Christopher Ndoleriire, Sedrack Matsiko, Brian Muhereza
}

Makerere University College of Health Sciences, Department of Ear, Nose and Throat

\section{ABSTRACT}

A pre-auricular sinus will rarely present in coexistence with a post-auricular dermoid cyst. The coexistence of a discharging pre-auricular sinus with a post-auricular dermoid cyst presents Makerere University College of a diagnostic challenge. Without meticulous history taking and Health Sciences, Department of physical exam, one would subject the patient to aggressive and Ear, Nose and Throat unwarranted investigation and management modalities as though the infected post-auricular dermoid cyst were a mastoid abscess. We present a 15-year-old male who presented to the ENT clinic of Mulago National Referral Hospital and was diagnosed with an infected pre-auricular sinus with an infected post-auricular dermoid cyst.

*Correspondence to Author:

Sedrack Matsiko

How to cite this article:

Christopher Ndoleriire, Sedrack Matsiko, Brian Muhereza. THE COEXISTENCE OF A PRE-AURICULAR SINUS WITH POST-AURICULAR DERMOID CYST. International Journal of Case Reports, 2020, 4: 126

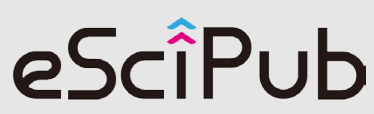

eSciPub LLC, Houston, TX USA. Website: https://escipub.com/ 


\section{INTRODUCTION}

A pre-auricular sinus will rarely present in coexistence with a post-auricular dermoid cyst. Despite head and neck dermoid cysts being uncommon, only about five to seven percent of them present with an auricular site ${ }^{1-2}$.

A pre-auricular sinus is a congenital anomaly resulting from aberrant fusion the auricular hillocks of His. It commonly occurs in males, anterior to the helical crus on the right side and in isolation from other congenital anomalies. Pre-auricular sinuses remain asymptomatic most of the time. Pre-auricular sinuses that get infected often result in recurrent infections recalcitrant to antibiotic therapy and only amenable to surgical excision ${ }^{3}$.
Congenital dermoid cysts result from entrapment of epidermal elements such as hair follicles, sweat glands, and sebaceous glands within embryonal fusion planes. Just like preauricular sinuses, dermoid cysts remain asymptomatic for the most part ${ }^{1,2,4}$. Only a small proportion of head and neck dermoid cysts present around the ear let alone coexisting with another congenital anomaly.

The coexistence of a pre-auricular sinus with a post-auricular dermoid cyst presents a diagnostic challenge and may be confused with a post-auricular mastoid abscess. We present a 15-year-old male who presented to the ENT clinic of Mulago National Referral Hospital with a pre-auricular sinus coexisting with a postauricular congenital dermoid cyst.
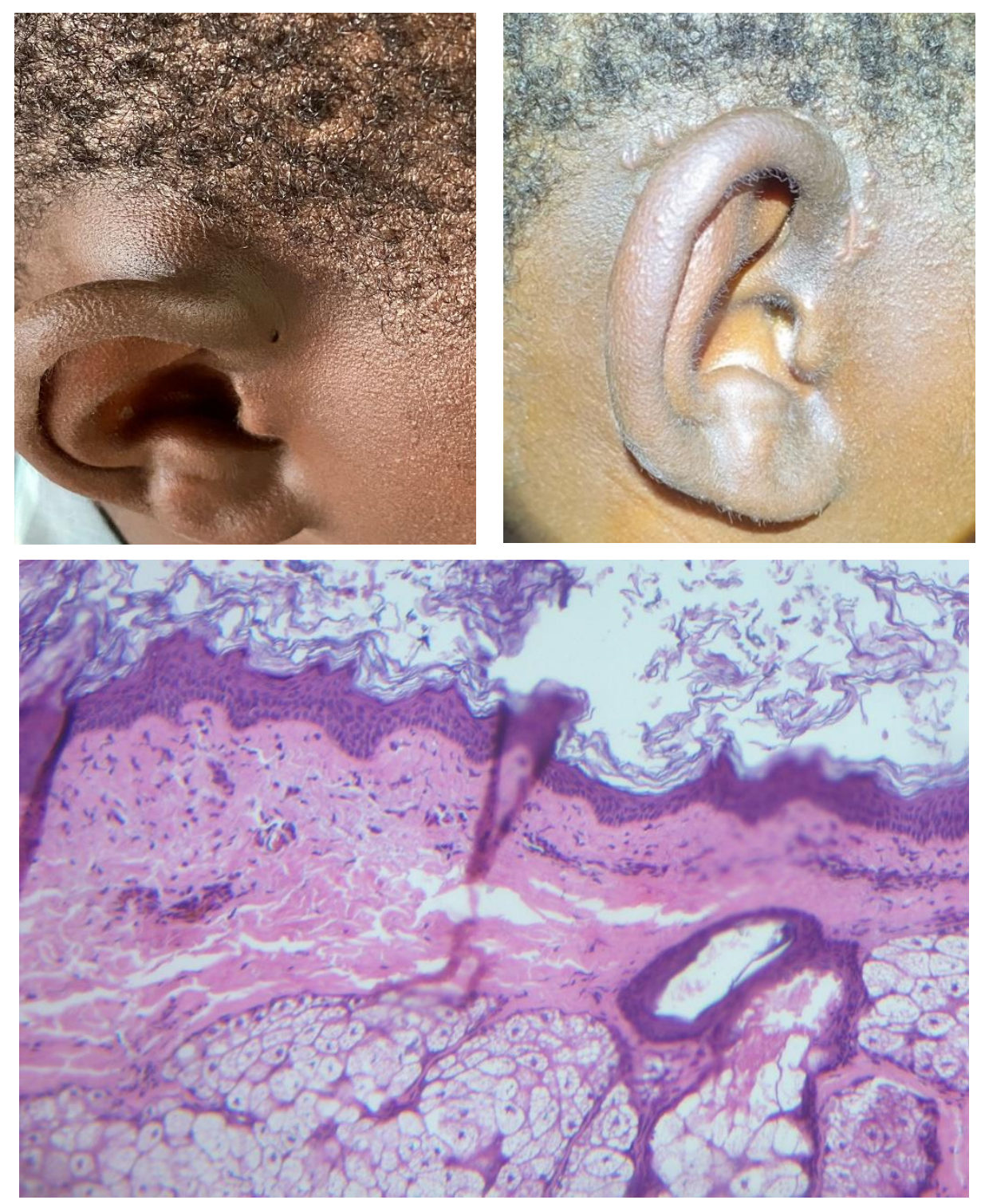


\section{CASE REPORT}

A 15-year-old male presented with complaints of painful pus discharging sinus in front of the right ear associated with a painful swelling at the back of the same ear. He had had both the sinus in front of the ear and the swelling behind his ear since birth. The swelling was initially neither bothersome nor increasing in size. Over the past three years, the sinus occasionally discharged pus and became painful. These symptoms were relieved by antibiotics and analgesia but had now become more frequent. He stated that he had ipsilateral ear pain but no ear discharge or reduced hearing.

On examination, he had a tender pusdischarging pre-auricular sinus anterior to the crus of the helix. He also had a smooth, round, doughy and tender post-auricular mass that was $4 \mathrm{~cm}$ along its widest diameter. The rest of the physical examination and systemic examination were found to be unremarkably normal. He was managed with an incision and drainage and initiated on a course of antibiotics and analgesia.

Four weeks later he was reviewed and found to have a dried up sinus with a persisting component of the post-auricular mass that was now non-tender. The pre-auricular sinus and the post-auricular mass were excised under local anesthesia. After an auriculotemporal nerve block, a vertical elliptical skin incision around the sinus was extended vertically and carried along the supra-auricular skin crease over the maximum bulge of the post-auricular mass.

Superior and anterior to the sinus, sharp dissection was carried to the temporalis fascia. Dissection was carried posteroinferior separating the soft tissue from temporalis fascia till the helical cartilage was exposed. Soft tissue was dissected off the helical cartilage along the perichondrium. The sinus was excised with a splinter of cartilage from the helical crus. By blunt dissection, the post-auricular mass was excised after releasing it from the overlying superficial musculoaponeurotic system fascia and the underlying temporalis fascia. The operation site was closed in layers and skin closed with simple interrupted sutures.

Macroscopy of the excised cyst revealed a piece of tissue measuring $2.5 \mathrm{~cm}$ by $1 \mathrm{~cm}$ by $0.5 \mathrm{~cm}$. The cyst was grey-brown and of soft consistency. The cut surface was cystic with solid areas. The cystic areas contain gelatinous material. Microscopy revealed a squamous epithelium lined cyst with pilosebaceous units. There was keratinous debris and benign lymphoid aggregates. A histological diagnosis of a dermoid cyst was made.

\section{DISCUSSION}

A pre-auricular sinus or an auricular dermoid cyst will commonly occur in isolation. The coexistence of a pre-auricular sinus with a dermoid cyst has a rare occurrence. A pus discharging pre-auricular sinus presenting with a postauricular mass makes the differential broader.

Only less than ten percent of pre-auricular sinuses present with sacs posterior to the external auditory canal. The pit of these preauricular sinuses is classically located posterior to a vertical line joining the tragus posterior margin of the helical crus ${ }^{3}$. The sinus pit of our patient was located anterior to the helical crus despite having a sac that was extending posteriorly to the helical crus.

Auricular sites represent about five to seven percent of all head and neck dermoid cysts ${ }^{1-2}$. A dermoid cyst is always low ranking on the list of differentials for a post-auricular mass due to its infrequent presentation. The patient presented with an infected post-auricular dermoid cyst whose infection was attributable to the contiguous spread from the posterior projection of the infected pre-auricular sinus' sac.

In settings with a high prevalence of chronic suppurative otitis media, without meticulous history taking to establish the temporal relationship between the symptoms and signs, one would subject the patient to aggressive and unwarranted investigation and management modalities as though the infected post-auricular dermoid cyst were a mastoid abscess. 


\section{CONCLUSION}

History and physical exam are indispensable in reaching a correct diagnosis when presented with an infected pre-auricular sinus associated with a post-auricular mass especially in lowincome settings where chronically discharging ears are prevalent and modern investigative modalities may not be readily present.

\section{REFERENCES}

1. June SC, Yong CB, Jae WL et al. Dermoid cysts: Epidemiology and diagnostic approach based on clinical experiences. Arch Plast Surg. 2018 Nov; 45(6): $512-516$

2. Wisecarver et al. Posterior Auricular Mass. www.ePlasty.com, Interesting Case, June 22, 2017

3. Ng WSJ, Chew YK, Tan KL et al. Pre-Auricular Sinus: An Uncommon Presentation. Malays Fan Physician. 2011; 6(1): 32-33

4. Yesun C \& Dong-Hee L. Clinical characteristics of Idiopathic Epidermoid and Dermoid Cysts of the Ear. J Audiol Otol. 2017 July; 22(2): 77-80

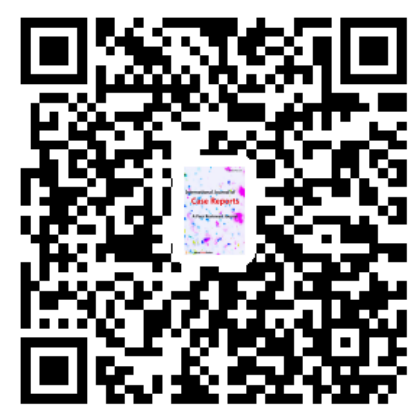

